\title{
An Ordered Crystal Structure of IRMOF-3
}

\author{
Haneul Yim, Eunyoung Kang, and Jaheon Kim* \\ Department of Chemistry, Soongsil University, Seoul 156-743, Korea. *E-mail: jaheon@ssu.ac.kr \\ Received July 3, 2009, Accepted January 18, 2010
}

Key Words: MOF, Zn(II), 2-Amino-1,4-terephthalic acid, Crystal structure, Polymorph

Polymorphism is the existence of more than one crystal structure of a compound, and frequently, difficulties are encountered in reproducing the crystallization of some polymorphs. ${ }^{1}$ However, there is a steady interest in this phenomenon because a better understanding and control over polymorphs will lead to the development of functional materials such as pharmaceuticals, energetic materials, pigments, and so on. ${ }^{2}$ The metal-organic frameworks (MOFs) could also exhibit structural diversities for the same building blocks because this phenomenon has observed for all types of crystals. For example, $\mathrm{Mg}$ and 2,6-naphthalenedicarboxylate (NDC) can be assembled to produce 2D and 3D MOFs with the same framework entities, $\mathrm{Mg}_{3}(\mathrm{NDC})_{3}$ and the same SBUs (secondary building blocks). ${ }^{3}$ However, the difference between the coordinating solvents for the $\mathrm{Mg}$ ions of the two MOFs is a key factor that induces large structural changes. In this study, the crystal structure of an ordered IRMOF-3 (hereafter, $\alpha$-IRMOF-3) was examined. This compound was a rare example of polymorphism because its formula, $\mathrm{Zn}_{4} \mathrm{O}\left(\mathrm{H}_{2} \mathrm{~N}-\mathrm{BDC}\right)_{3}\left(\mathrm{H}_{2} \mathrm{~N}\right.$-BDC, 2-amino-1,4-benzenedicarboxylate), SBUs and connectivity patterns were nearly the same as a known IRMOF- $3,{ }^{4}$ but ordered structure was different than the disordered IRMOF-3 (Figure 1).

IRMOF-3 belongs to a cubic crystal system, and its space group, $F m(-3) m$ (No. 225), requires a random orientation of $\mathrm{H}_{2} \mathrm{~N}-\mathrm{BDC}$. ${ }^{4}$ Other IRMOFs are generally formulated as $\mathrm{Zn}_{4} \mathrm{O}$ $(\mathrm{L})_{3}(\mathrm{~L}=$ ditopic aromatic carboxylate) with non-interpenetrating frameworks and belong to the same space group, implying that the random location of the organic linkers produces the most stable framework structures when they join the $\mathrm{Zn}_{4} \mathrm{O}$ moieties in the lattice. ${ }^{4}$ However, $\alpha$-IRMOF- 3 belongs to a cubic $P a(-3)$ (No. 205) space group (Table 1) and contains ordered $\mathrm{H}_{2} \mathrm{~N}-\mathrm{BDC}$ ligands. This ligand ordering required an uneven arrangement of the six $\mathrm{H}_{2} \mathrm{~N}-\mathrm{BDCs}$ around the $\mathrm{Zn}_{4} \mathrm{O}$ cluster in Figure 1(d). Therefore, among the six $\mathrm{H}_{2} \mathrm{~N}-\mathrm{BDCs}$, three of them have their amino groups closer to the $\mathrm{Zn}_{4} \mathrm{O}$, whereas the remaining ones directly neighbor the $\mathrm{Zn}_{4} \mathrm{O}$ clusters. The $-\mathrm{NH}_{2}$ participated in a hydrogen bond with one of the carboxylate oxygen atoms: $\mathrm{N}-\mathrm{H} \cdots \mathrm{O}: \mathrm{N}-\mathrm{H}=0.88 \AA, \mathrm{H} \cdots \mathrm{O}=1.85 \AA, \mathrm{N} \cdots \mathrm{O}=$ $2.51(3) \AA, \angle(\mathrm{NHO})=130.1^{\circ}$. The localization of the three hydrogen bonds lowers the symmetry of the SBU in $\alpha$-IRMOF-3, which leads to the distortion of the framework. In contrast, the undistorted framework in IRMOF-3 is ascribed to the random distribution of hydrogen bonds around the inorganic SBU.

After the different structures of $\alpha$-IRMOF-3 and IRMOF-3 were confirmed, the reproducible synthetic conditions were investigated using the XRD patterns for each sample at different reaction conditions. The XRD patterns for IRMOF-3 and $\alpha$ IRMOF-3 must be different from each other because the primitive lattice ( $\alpha$-IRMOF-3) did not have the systematic absences that were present in the face-centered one (IRMOF-3) in Fi- (a)

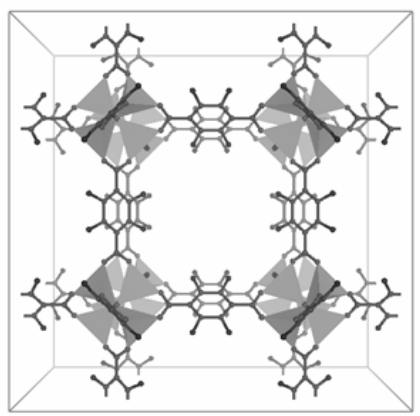

(c)

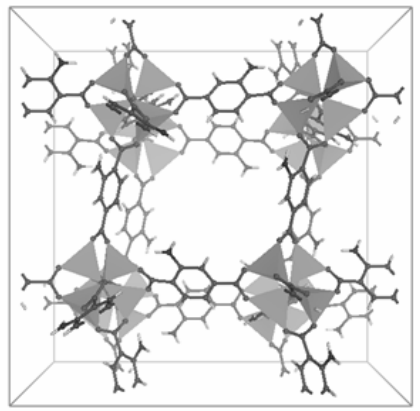

(b)

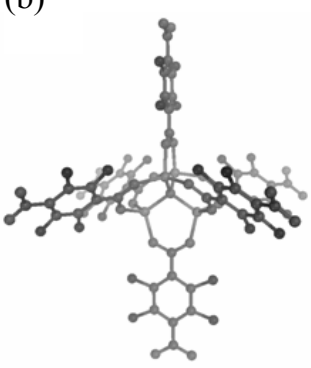

(d)

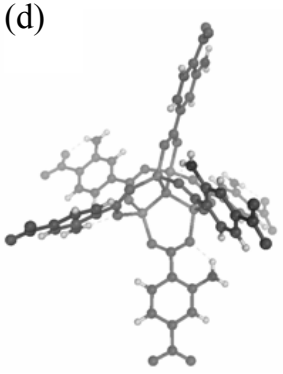

Figure 1. (a) Unit cell packing and (b) fragment enclosing of the SBU of IRMOF-3 with significant distortion of (c) the framework and (d) the SBU of $\alpha$-IRMOF-3. The Zn atoms were tetrahedral in both (a) and (c). The amino group was disordered over the four sites in the phenylene ring of IRMOF-3, and the balls representing the $\mathrm{N}$ atoms in both (a) and (b) had site occupancy factors of 1/4.

Table 1. Comparison of the crystal data for IRMOF-3 and $\alpha$-IRMOF-3.

\begin{tabular}{lll}
\hline & IRMOF-3 & $\alpha$-IRMOF-3 \\
\hline Formula & $\mathrm{Zn}_{4} \mathrm{O}\left(\mathrm{H}_{2} \mathrm{~N}-\mathrm{BDC}\right)_{3}$ & $\mathrm{Zn}_{4} \mathrm{O}\left(\mathrm{H}_{2} \mathrm{~N}-\mathrm{BDC}\right)_{3}$ \\
Crystal system & Cubic & $\mathrm{Cubic}$ \\
Space group & $F m(-3) m$ & $\mathrm{~Pa}(-3)$ \\
$\mathrm{Z}$ & 8 & 8 \\
$a, \AA$ & $25.7465(14)$ & $25.0872(10)$ \\
$V, \AA^{3}$ & $17066.9(16)$ & $15789.1(11)$ \\
$T, \mathrm{~K}$ & 273 & 173 \\
Source & Ref. 4 & This work \\
\hline
\end{tabular}



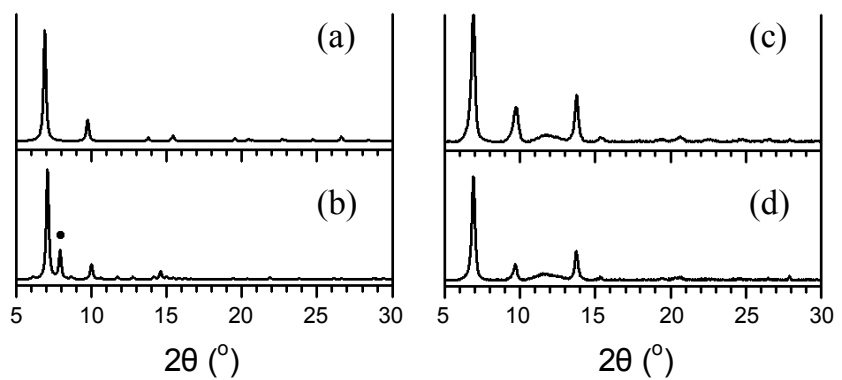

Figure 2. Simulated XRD patterns for (a) IRMOF-3 and (b) $\alpha$ IRMOF-3. Observed patterns for (c) IRMOF-3 and (d) bulk crystals that were collected after the test reaction searching for $\alpha$-IRMOF-3. The $(210)$ reflection $(\bullet)$ in (b) is not allowed for a face-centered lattice. The broad peaks in (c) and (d) at around $12^{\circ}$ were caused by presence of the solvent among the crystallites. A Rigaku Miniflex diffractometer $(\mathrm{Cu} \mathrm{K} \alpha$ radiation) was used for the measurements.

gures 2(a) and 2(b). However, the reproducible preparation of $\alpha$-IRMOF- 3 could not be determined. In the XRD measurements, the patterns for the minor products in bulk shall not be easily identified because the small amount that is present in the product mixture does not produce strong diffraction peaks.

In summary, a MOF crystal with a structure that was very similar to the known IRMOF-3 was obtained by chance. The lack of disorder in the organic linkers of the crystal structure resulted in a distorted framework compared to IRMOF-3 and the reduced crystal symmetry. However, this polymorph of IRMOF-3 was not successfully reproduced after many trials because the polymorph crystals are easily overlooked, or a more extensive effort must be made in order to determine the reproducible crystallization conditions. ${ }^{1}$

\section{Experimental Section}

Preparation of IRMOF-3. $\mathrm{Zn}\left(\mathrm{NO}_{3}\right)_{2} \cdot 6 \mathrm{H}_{2} \mathrm{O}(200 \mathrm{mg}, 0.67$ $\mathrm{mmol})$ and 2-amino-1,4-terephthalic acid $\left(\mathrm{H}_{2} \mathrm{~N}-\mathrm{BDCH}_{2}, 40 \mathrm{mg}\right.$, $0.22 \mathrm{mmol})$ were dissolved in DMF $(10.0 \mathrm{~mL})$, and the reaction mixture was heated at $105^{\circ} \mathrm{C}$ for 48 hours to give cubic crystals as a product.

A trial reaction for obtaining $\alpha$-IRMOF-3. First, $\mathrm{Zn}\left(\mathrm{NO}_{3}\right)_{2}$. $6 \mathrm{H}_{2} \mathrm{O}(200 \mathrm{mg}, 0.67 \mathrm{mmol})$ and 2-amino-1,4-terephthalic acid (40 mg, $0.22 \mathrm{mmol}$ ) were dissolved in DMF (10.0 mL). Into the solution, an additive such as pyrazine $(30 \mathrm{mg}, 0.27 \mathrm{mmol})$ was added and the reaction mixture was heated at $105^{\circ} \mathrm{C}$ for 48 hours to give cubic crystals as a product.

Single crystal X-ray analysis of $\boldsymbol{\alpha}$-IRMOF-3. A 1265 frame data set was collected for the colorless cubic crystal at $173 \mathrm{~K}$ using a Bruker SMART CCD diffractometer with MoKa radiation $(\lambda=0.71073 \AA)$. The Bruker SMART program ${ }^{5}$ was used to collect the data, and SAINT ${ }^{6}$ was used for the cell refinement and reduction. The absorption correction was applied using SADABS. ${ }^{7}$ The crystal structure was determined using the SHELX-TL software package ${ }^{8}$ with a cubic space group,
$P a(-3)$ (No. 205). The peak integration was conducted up to a resolution limit of $1.0 \AA$ A because very weak diffraction occurred at higher $2 \theta$ angles. $\mathrm{Zn}$ ions were found using the Patterson methods with XS, and the other framework atoms were found from the successive difference in the Fourier syntheses. The refinement was conducted using XL. Although the framework of atoms, except for $\mathrm{H}$, were found and ansiotropically refined except for $\mathrm{H}$ atoms, the $\mathrm{R}_{1}$ value was very high (30\%). The introduction of the TWIN and BASF instructions for the merohedral twin lowered the $\mathrm{R}_{1}$ value to $19 \%$. The PLATON SQUEEZE routine was used to extract the contribution of the solvents in the intensity data because these solvents were not easily defined in the porous compound. ${ }^{9}$ This treatment reduced the $\mathrm{R}_{1}$ value again to $\sim 10 \%$. To fix the distortion of the aromatic ring, geometric restraints (DFIX and FLAT) were applied. The thermal ellipsoids were rather eccentric, and some of them were restrained with ISOR. All of these abnormal results were ascribed to the twin nature of the crystal. Crystal data for $\alpha$-IRMOF-3: $\mathrm{C}_{24} \mathrm{H}_{15} \mathrm{~N}_{3} \mathrm{O}_{13} \mathrm{Zn}_{4}, f w=814.87$, cubic $P a(-3)$ (No. 205), $Z=8$, $T=173 \mathrm{~K}, \lambda(\mathrm{Mo} \mathrm{K} \alpha)=0.71073 \AA, a=25.0872(10) \AA, V=$ $15789.1(11) \AA^{3}, d_{\text {calcd }}=0.686 \mathrm{~g} / \mathrm{cm}^{3}, \mu(\mathrm{Mo} \mathrm{K} \alpha)=1.227 \mathrm{~mm}^{-1}$, $\mathrm{F}(000)=3232$, Bruker SMART CCD diffractometer, 52270 reflections measured, 2781 independent $\left(\mathrm{R}_{\text {int }}=0.1045\right)$. Final $\mathrm{R}_{1}=0.1094, w \mathrm{R}_{2}=0.2871$ for $I>2 \sigma(I), \mathrm{GOF}=1.178$. The crystallographic data (CIF) for $\alpha$-IRMOF-3 has been provided to the Cambridge Crystallographic Data Centre, CCDC No. 738809. Copies of the data can be obtained free of charge by contacting CCDC, 12 Union road, Cambridge CB2 1EZ, UK (fax: +44 1223336 033; e-mail: deposit@ccdc.cam.ac.uk), or electronically via www.ccdc.cam.ac.uk/data_request/cif.

Acknowledgments. This research was financially supported by the Ministry of Knowledge Economy (MKE) and Korea Institute for Advancement of Technology (KIAT) through the Human Resource Training Project for Strategic Technology.

\section{References}

1. Dunitz, J. D.; Bernstein, J. Acc. Chem. Res. 1995, 28, 193-200.

2. Various examples of polymorphism have been collected under the title of Special Issue: Facets of Polymorphism in Crystals in Cryst. Growth \& Des. 2008, 8, 1-362.

3. Senkovska, I.; Fritsch, J.; Kaskel, S. Eur. J. Inorg. Chem. 2007, 5475-5479.

4. Eddaoudi, M.; Kim, J.; Rosi, N. L.; Vodak, D. T.; Wachter, J.; O'Keeffe, M.; Yaghi, O. M. Science 2002, 295, 469-472.

5. Bruker SMART version 5.625, Area-Detector Software Package; Bruker AXS 1997-2001. Madison, WI, USA.

6. Bruker SAINT+ version 6.04. SAX Area-Detector Integration Program. Bruker AXS 1997-2001. Madison, WI, USA.

7. Sheldrick, G. M. SADABS version 2.03, a Program for Empirical Absorption Correction; Universität Göttingen, 1997-2001.

8. Bruker AXS SHELXTL version 6.10. Structure Determination Package. Bruker AXS 2000. Madison, WI, USA.

9. Spek, A. L. (2008) PLATON, A Multipurpose Crystallographic Tool, Utrecht University, Utrecht, The Netherlands. 